\title{
CORTICAL TENTING TECHNIQUE FOR VERTICAL AUGMENTATION OF ATROPHIC POSTERIOR PART OF THE MANDIBLE (CLINICAL TRIAL)
}

\author{
John K. Hares ${ }^{1}$ BDS, Sherif S. Mohamed ${ }^{2} P h D$, Marwa G. Noureldin ${ }^{3}$ PhD
}

\begin{abstract}
INTRODUCTION: The progressive decrease in the alveolar bone volume after tooth loss impedes the use of dental implants for rehabilitation of edentulous regions. This fact is of utmost significance in the posterior areas of mandible, where the presence of inferior alveolar nerve further complicates the proper insertion of dental implants. Considering the drawbacks of the non-reconstructive treatment options, restoring deficits of alveolar ridges by reconstructive procedures might still be more practicable, despite the invasiveness. The majority of reconstructive techniques involve a process of bone grafting and vertical ridge augmentation. Cortical tenting technique is used for vertical ridge augmentation and can achieve a good degree of success.

OBJECTIVES: To evaluate the effectiveness of cortical tenting technique in vertical ridge augmentation of atrophic posterior mandibles.

METHODS: The study was made on ten patients with atrophic posterior part of the mandible. In each one of them, the atrophic alveolar ridge will be treated with cortical tenting technique. Bone height over the mandibular canal was measured on Standardized CBCT scans taken preoperatively (base line), and 1 week and 4 months postoperatively and bone density was measured at grafted area 4 months postoperatively.

RESULTS: The average final bone gain was $4.540 \mathrm{~mm}$ at the end of follow up period with 1.700 mm average of graft resorption. Estimated bone density was measured also at grafted area 4 months after surgery with a mean value of 398.59 voxel value (VV).

CONCLUSION: The use of cortical block graft taken from the ramus of the mandible to augment vertical bone defect in the posterior of the mandible has significant success rates.
\end{abstract}

KEYWORDS: Vertical augmentation, Cortical tenting, Atrophic mandible, Piezosurgery.

1.BDS, 2014, Faculty of Dentistry, Alexandria University.

2.Professor of Oral and Maxillofacial Surgery, Department of Oral and Maxillofacial Surgery Faculty of Dentistry, Alexandria University, Egypt.

3.Lecturer of Oral and Maxillofacial Surgery, Department of Oral and Maxillofacial Surgery Faculty of Dentistry, Alexandria University, Egypt

*Corresponding author

john.kamal12@yahoo.com

\section{INTRODUCTION}

Tooth extraction is considered to be the most common cause of ridge resorption._The bone loss that follows tooth loss or extraction occurs most rapidly within the first year and is 10fold greater than subsequent years (1). On average, $40 \%$ to $60 \%$ of ridge volume loss occurs within the first 3 years $(1,2)$. Generally, width deficiencies usually occur first, followed by height deficiencies at later stages of edentulism $(1,3)$.

The rehabilitation of atrophic posterior mandible represents today a hard challenge for clinicians. The gradual vertical and horizontal resorption of the mandibular bone crest in both partially and totally edentulous patients can be treated by several prosthetic and surgical options (4-6).

Patients can be rehabilitated with conventional partial removable dentures, but often this treatment does not meet the expectations of the patients (7).

Regarding implant supported treatment options, vertical ridge augmentation, the placement of short implants (8mm or less) and finally, surgical displacement of the inferior alveolar nerve could be necessary for the correction of the atrophic posterior mandible $(4,6,8)$.

Placement of short-length implants in areas with 7- to 8-mm bone over the inferior alveolar nerve canal minimizes the risk of nerve encroachment $(8,9)$. This treatment modality is, however, prone to criticism due to the dubious survival rate associated with short-length fixtures $(9,10)$.

Indeed, the displacement of the alveolar nerve is technically tough, and this procedure may be associated with certain degree of permanent loss of nerve sensitivity $(6,11-14)$.

Different surgical techniques are currently being used to augment the posterior mandible: alveolar distraction osteogenesis, guided bone regeneration (GBR), interpositional bone grafting and onlay bone grafting; however, only few of these have been tested in randomized clinical trial (RCT) $(15,16)$. 
Several surgical bone augmentation techniques are related to an unpredictable resorption of the grafted material. Vascularity seems to be the main factor in determining whether such a graft can be maintained in situ (12).

Within the last 2 decades, cortical tenting technique has been brought into the literature. In this technique, cortical blocks were tented over the bone graft material. This technique was approved to be effective in increasing the ridge width $(17,18)$.

Considering the scarcity of experiments evaluating cortical tenting technique in vertical ridge augmentation, this clinical and radiographic study is aimed to measure its efficacy for vertical augmentation of atrophic posterior mandibles.

\section{MATERIALS AND METHODS}

Study design: The study was a prospective randomized clinical trial. It was conducted on a sample consisting of ten patients with edentulous atrophic posterior mandible. Patients were selected from Oral and Maxillofacial Surgery Department, Faculty of Dentistry, Alexandria University.

All procedures were done after an informed consent for the patient and in accordance with the ethics research committee.

\section{Eligibility Criteria's}

\section{Inclusion criteria}

- Adult patients between 30 to 60 years of age.

- Patients with edentulous posterior mandible.

- Patients with residual ridge height $\leq 8 \mathrm{~mm}$ above the inferior alveolar canal measured by CBCT scans preoperatively.

\section{Exclusion criteria}

- Pregnant females.

- Patients with unstable systemic diseases (i.e., diabetes mellitus, cancer, human immunodeficiency syndrome, bone metabolic disorder, immunosuppressive therapy, chemotherapy, radiation).

- Patients with poor oral hygiene, parafunctional habits and any acute dental infection.

- Recent tooth extraction in posterior mandible within the last 3-4 months.

- Patients with inadequate bone width $(<3 \mathrm{~mm})$ measured by CBCT preoperatively.

\section{Materials}

1. Piezotome 2 piezo electrical surgery device and bone surgery kit (SATELEC, Acteon Co., France):

The bone surgery kit consists of six ultrasonic tips (three saws and three scalpels). The sterile spray helps to cool the tips (thus avoiding tissue damage from exposure to high temperatures) and provides excellent visibility of the operating field. It is used for performing bone graft; allow cutting excising and remodeling bone structures without any risk of soft tissue lesions.

2. Michigan O Probe (PREMINM Co., USA):

It is used for measurements during surgery. Markings include 1, 2,3,5,7,8 and 9mm with $4 \mathrm{~mm}$ and $6 \mathrm{~mm}$ missing.
3. Biphasic calcium phosphate bone graft (OVIS Bone BCP, DENTIS Co., USA).

4. NORMED titanium osteosynthesis system (Zimmer biomet holdings,Inc., Indiana, USA).

It supplies titanium osteosynthesis micro screws with diameter of $1.2 \mathrm{~mm} / 1.7 \mathrm{~mm} / 2.3 \mathrm{~mm} / 2.7 \mathrm{~mm}$, and length range of 3 $19 \mathrm{~mm}$

\section{Method}

\section{Preoperative phase}

History was taken and thorough intra oral and extra oral examinations were done for all patients. In addition, a preoperative CBCT (19) was done in the selected quadrant to measure the height of alveolar bone above the mandibular canal (Bone height 0; BH0) (Figure 1).

All patients were given oral hygiene instructions; furthermore, scaling and root planning were achieved two weeks before surgery.

Preoperative medications were prescribed including:

1. Intravenous Cefotaxime 1gm (each vial contains Cefotaxime 1gm, manufactured by E.I.P.I.C.O) (twice/day) one day before surgery.

2. Intramuscular $8 \mathrm{mg}$ of dexamethasone (each ampoule $8 \mathrm{mg} / 2 \mathrm{ml}$, manufactured by SIGMATEC) at the morning of surgery.

3. Chlorhexidine mouths wash $0.12 \%$ (Hexitol: chlorhexidine $125 \mathrm{mg} / 100 \mathrm{ml}$, concentration $0.125 \%$ : Arabic drug company, ADCO) (twice/day) for one week before surgery.

II. Operative procedure (20)

- All patients were treated under local anesthesia using $2 \%$ mepivacaine 1:20,000 levonordefrin (Septodont; Pennsylvania, USA).

1. A mid-crestal incision was made on the edentulous alveolar ridge with an intrasulcular extension to the adjacent teeth and an extension over the oblique ridge followed by full thickness flap elevation to gain access to the ramus area for graft harvesting.

2. To obtain cortical ramus blocks, vertical and horizontal osteotomies limited to the cortical bone were performed using piezotome 2 bone surgery kit (SATELEC, Acteon Co., France) under copious irrigation with saline (Figure 2A).

3. The graft was levered from its bed \& placed into saline till preparation of the recipient site. The graft thickness was at least $3 \mathrm{~mm}$ to allow the insertion of a stabilizing screw without risking the fracture of the bone segment, while its length and width were determined according to the alveolar defect.

4. The recipient site was prepared by decortication using drills under copious irrigation to enhance the vascularization of the augmented area (Figure 2B).

5. A periosteal elevator was placed between the bone block and the recipient site to maintain a $4 \mathrm{~mm}$ distance during fixation with microscrews (10-12mm in length).

6. The underlying gap was filled with biphasic calcium phosphate bone graft (OVIS Bone BCP, DENTIS Co., 
USA) (Figure 2C) and a platelet rich fibrin (PRF) membrane was used to cover the entire graft site.

7. A curved hemostat was used for blunt dissection of both buccal \& lingual flap followed by flap closure using (3-0) Vicryl suture (ETHICON, Inc., New Jersey, USA).

\section{Postoperative phase}

a) Post-operative care: All patients were instructed to apply ice packs extra-orally for 12 hours.

\section{b)Post-operative medication:}

1. Intravenous Cefotaxime 1gm (each vial contains Cefotaxime 1gm, manufactured by E.I.P.I.C.O) (twice/day) one day after surgery followed by $1 \mathrm{gm}$ amoxicillin+ clavulanic acid tablets (Augmentin: Amoxicillin 875mg+Clavulanic acid 125mg: GlaxoSmithKline, UK) (twice/day) for the next 6 days.

2. Metronidazole 500mg tablets (Flagyl: metronidazole $500 \mathrm{mg}$, GlaxoSmithKline, UK) (3times/day) for 5 days.

3. $\alpha$-chemo-trypsin ampules (Leurquin France, packed by Amoun pharmaceutical CO.S.A.E-Egypt) as anti-edematous once daily for 5 days.

4. Intramuscular $75 \mathrm{mg}$ diclofenac sodium (Voltaren: each ampoule $75 \mathrm{mg} / 3 \mathrm{ml}$, manufactured by NOVARTISSwitzerland) (twice/day) one day after surgery followed by diclofenac potassium 50mg tablets (Cataflam: Diclofenac potassium 50mg: NOVARTIS-Switzerland) (3 times/day) for 6 days.

The patients were also instructed to use Chlorhexidine mouthwash $0.12 \%$ (Hexitol: chlorhexidine $125 \mathrm{mg} / 100 \mathrm{ml}$, concentration $0.125 \%$ : Arabic drug company, ADCO) (twice/day) for a week from the day after surgery.

c) Post-operative follow up:

- Sutures were removed 14 days after surgery.

- The patients were recalled for postoperative check-ups one time per week during the first month, and the follow-up examinations were continued at a monthly interval.

- A 4-month healing period was considered for graft integration.

IV. Radiographic evaluation (19)

- The height of alveolar bone over the mandibular canal was measured again using CBCT scans taken 1 week after ridge augmentation (BH1) (Figure 3), and 4 months postoperatively (BH2) (Figure 4).

- Using BH0 measurements taken preoperatively, the amount of initial vertical deficiency from the alveolar nerve was calculated.

- The amount of bone augmentation 1 week after surgery, considered as the initial bone gain was calculated (BH1 $\mathrm{BH} 0$ ).

- The amount of final bone gain (BH2-BH0) was also measured.

- The difference between the initial and the final bone gain (BH2 - BH1) demonstrated the amount of graft resorption within the 4-month healing period.

- Bone density was also measured at the grafted area 4 months after surgery (BD).
- To minimize the effect of radiographic magnification on the accomplished results, all CBCT scans were taken in the same radiology center, using the same device and the same software (On demand 3D) (Cybermed, Inc., Seoul, Korea).

\section{Statistical Analysis of the data}

Data was fed to the computer and analyzed using International Business Machines Statistical Package for the Social Sciences (IBM SPSS) software package version 20.0.(Armonl, NY: IBM Corp) Qualitative data were described using number and percent. Quantitative data were described using range (minimum and maximum), mean, median and standard deviation.

The used test was Wilcoxon Signed Rank Test.

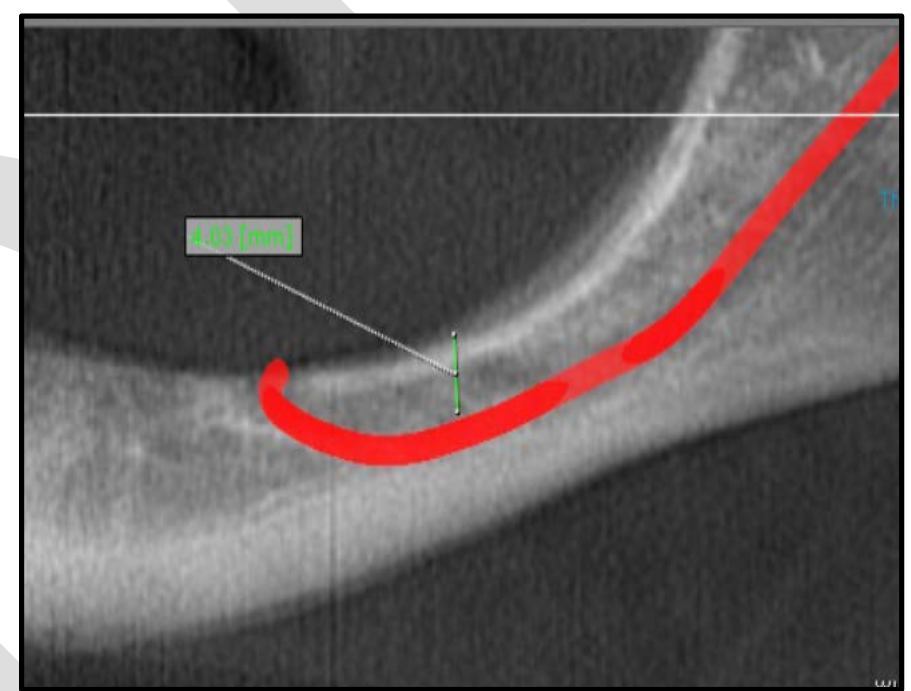

Figure (1): Preoperative CBCT showing bone defect and height of alveolar bone above the mandibular canal (BH0).

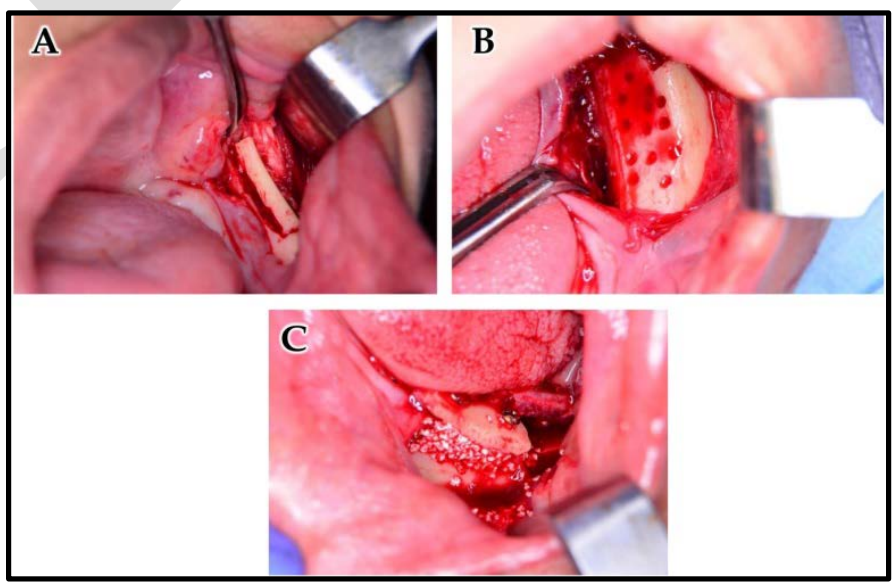

Figure (2): (A) The 2 vertical osteotomies were then connected to each other by one crestal horizontal osteotomy using BS1 tip and one buccal horizontal osteotomy using BS2L tip. (B) Decortication of recipient site was done by rounded surgical bur under copious irrigation. (C) Synthetic bone graft was placed in the space between the cortical graft and the recipient site. 


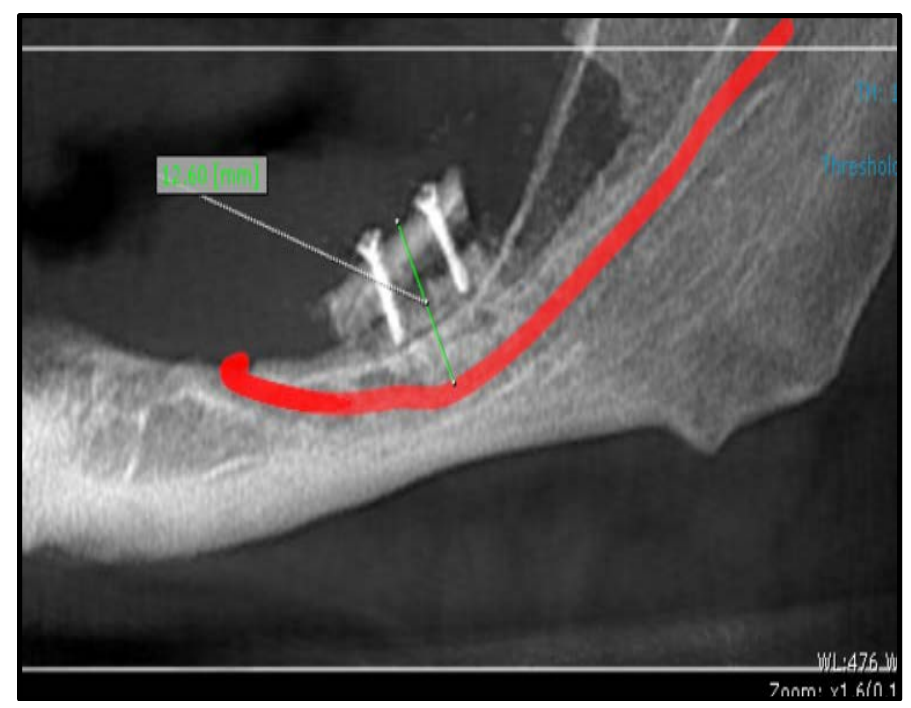

Figure (3): Post-operative CBCT, 1 week after surgery, with measurement of height of alveolar bone above the mandibular canal (BH1).

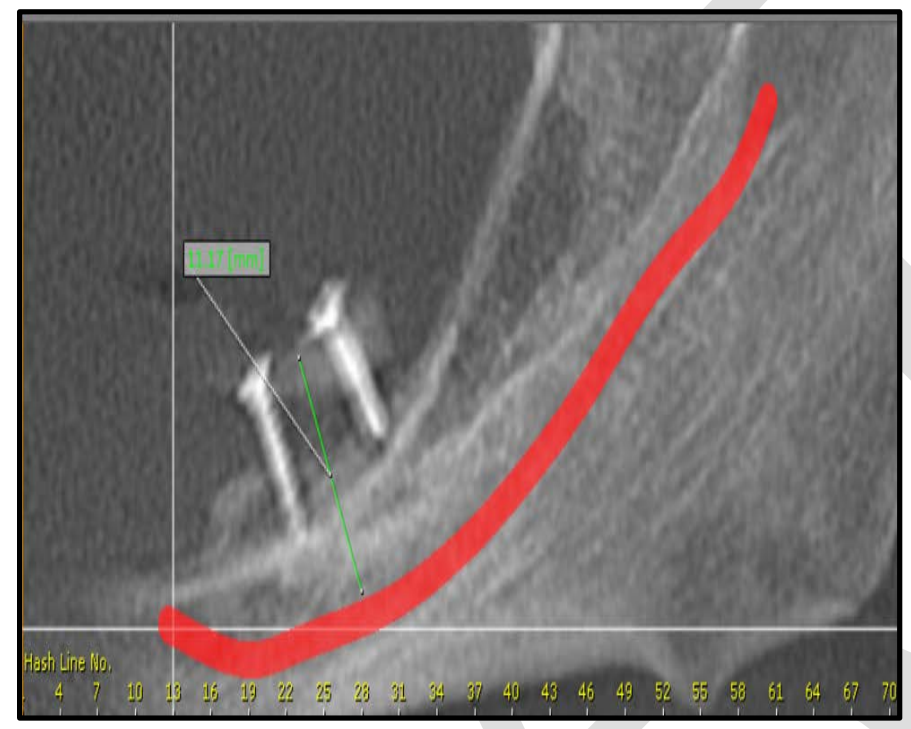

Figure (4): Post-operative CBCT, 4 months after surgery, with measurement of alveolar bone above the mandibular canal (BH2).

\section{RESULTS}

A total of 10 patients had vertical bone defect in the posterior part of the mandible were treated by vertical bone augmentation. The selected patients' age ranged from 30 to 55 years. They were 4 females and 6 males. All patients had adequate bone width with vertical bone defect resulted from early teeth loss or trauma. Two of the patients were partially edentulous while eight of them were completely edentulous. The technique used was cortical tenting technique in which autogenous bone graft harvested from the ramus of the mandible was used \& fixed $3 \mathrm{~mm}$ away from recipient site by miniscrews. The space between the graft \& recipient site was then filled with synthetic bone graft. All patients had been operated under local anesthesia. All patients were followed up radiographically for 4 months.

\section{Assessment of the bone height pre-operatively and post- operatively}

Data were collected regarding the bone height pre-operatively, 1 week post-operatively and at 4 months post operatively for the grafted area.

In the pre-operative measurements (BH0), the median was $5.750 \mathrm{~mm}$ with a minimum value of $4.5 \mathrm{~mm}$, a maximum value of $6.2 \mathrm{~mm}$ and an interquartile range of 0.6 .

In the measurements 1 week post-operatively (BH1), the median was $12.150 \mathrm{~mm}$ with a minimum value of 11.4 $\mathrm{mm}$, a maximum value of $12.6 \mathrm{~mm}$ and an interquartile range of 0.6 .

In the measurements 4 months post-operatively (BH2), the median was $10.550 \mathrm{~mm}$ with a minimum value of $7.0 \mathrm{~mm}$, a maximum value of $11.2 \mathrm{~mm}$ and an interquartile range of 1.0 .

The differences between pre-operative measurements (BH0) and 1week post-operative measurements (BH1) were statistically significant $(\mathrm{p}=0.005)$ (Table 1$)$.

The differences between pre-operative measurements (BH0) and 4 months post-operative measurements (BH2) were statistically significant ( $\mathrm{p}=0.005)$ (Table 2).

The comparison between pre-operative, 1 week and 4 months post-operative measurements are shown in (Figure 5).

2. Assessment of initial bone gain (BH1 - BH0) and final bone gain ( $\mathrm{BH} 2$ - $\mathrm{BH} 0)$

Using measurements taken preoperatively (BH0) and 1 week post-operatively (BH1), The amount of bone augmentation 1 week after surgery, considered as the initial bone gain was calculated (BH1 - BH0). Using measurements taken preoperatively (BH0) and 4 months post-operatively (BH2), the final bone gain was also calculated $(\mathrm{BH} 2-\mathrm{BH} 0)$.

In the initial bone gain measurements, the median was $6.450 \mathrm{~mm}$ with a minimum value of $5.5 \mathrm{~mm}$, a maximum value of $8.1 \mathrm{~mm}$ and an interquartile range of 0.8 .

In the final bone gain measurements, the median was 4.550 $\mathrm{mm}$ with a minimum value of $1.1 \mathrm{~mm}$, a maximum value of $6.5 \mathrm{~mm}$ and an interquartile range of 1.1 .

The differences between initial bone gain measurements (BH1-BH0) and final bone gain measurements (BH2-BH0) were statistically significant $(\mathrm{p}=0.008)$ (Table 3$)$.

\section{Assessment of amount of graft resorption (BH2-BH1)}

Using measurements taken 1 week post operatively (BH1) and 4 months post-operatively (BH2), The amount of graft resorption within 4 months healing period was calculated (BH2 - BH0).

In the amount of graft resorption measurements, the mean was $1.700 \mathrm{~mm}$ with a minimum value of $1.3 \mathrm{~mm}$, a maximum value of $4.4 \mathrm{~mm}$ and an interquartile range of 0.5 .

The differences between 1 week post-operative (BH1) and 4 months post-operative measurements (BH2) were statistically significant $(\mathrm{p}=0.008)$. 


\section{Assessment of bone density at grafted area}

Bone density was measured at grafted area above the recipient site at the end of follow up period. It was measured in voxel value (VV) from CBCT by using on demand 3D program (Cybermed, Inc., Seoul, Korea).

In the measurements of estimated average bone density, the mean was $398.59 \mathrm{VV}$ with a minimum value of 214.6, VV, a maximum value of $604.1 \mathrm{VV}$ and a standard of deviation value of 125.29 .

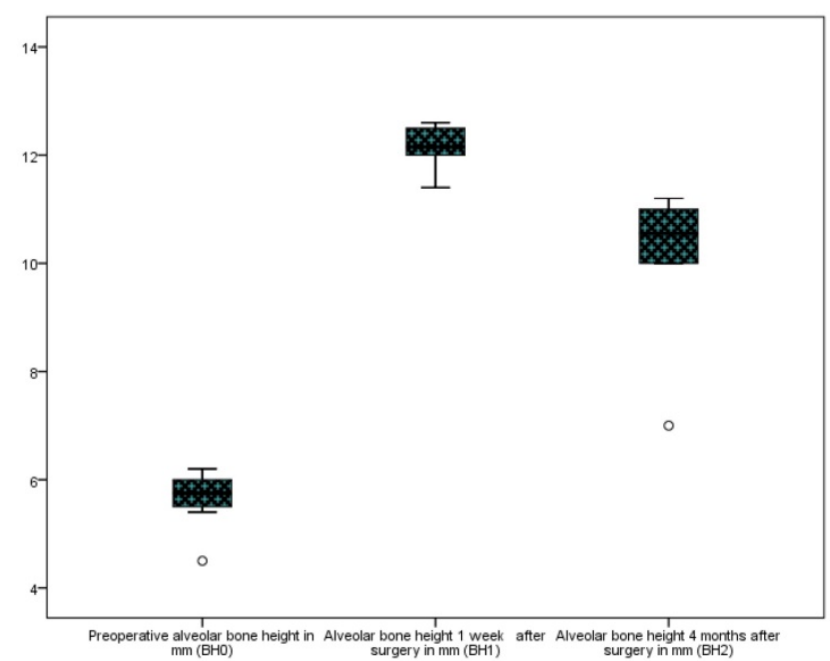

Figure (5): Comparison between pre-operative, 1 week and 4 months post-operative measurements according to radiographic bone assessment $(\mathrm{mm})(\mathrm{n}=10)$.

Table (1): Comparison between pre-operative and 1 week post-operative measurements according to Radiographic bone assessment (mm) $(\mathrm{n}=10)$.

\begin{tabular}{|c|c|c|c|c|c|c|}
\hline & \multirow{2}{*}{$\begin{array}{c}\text { Media } \\
\mathbf{n}\end{array}$} & \multirow{2}{*}{$\underset{\mathbf{m}}{\operatorname{Minimu}}$} & \multirow{2}{*}{$\underset{\mathbf{m}}{\operatorname{Maximu}}$} & \multicolumn{2}{|c|}{ Percentiles } & \multirow{2}{*}{\begin{tabular}{|c} 
Statistical \\
$\begin{array}{c}\text { Significanc } \\
\text { e }\end{array}$ \\
\end{tabular}} \\
\hline & & & & $25^{\text {th }}$ & $75^{\text {th }}$ & \\
\hline \begin{tabular}{|c|} 
Preoperativ \\
e alveolar \\
bone height \\
in mm \\
(BH0) \\
\end{tabular} & 5.750 & 4.5 & 6.2 & 5.475 & 6.050 & $0.005^{* *}$ \\
\hline \begin{tabular}{|c|} 
Alveolar \\
bone height \\
1 week after \\
surgery in \\
mm $(\mathrm{BH} 1)$ \\
\end{tabular} & 12.150 & 11.4 & 12.6 & $\begin{array}{c}11.95 \\
0\end{array}$ & $\begin{array}{c}12.50 \\
0\end{array}$ & \\
\hline
\end{tabular}

**Statistical Test: Wilcoxon Signed Rank Test $(\mathrm{z}=-2.802)$

${ }^{* *} \mathrm{p}<0.05$ was considered significant

Table (2): Comparison between pre-operative and 4 months post-operative measurements according to Radiographic bone assessment $(\mathrm{mm})(\mathrm{n}=10)$.

\begin{tabular}{|c|c|c|c|c|c|c|}
\hline & \multirow{2}{*}{$\begin{array}{c}\text { Media } \\
\text { n }\end{array}$} & \multirow{2}{*}{$\underset{\mathbf{m}}{\operatorname{Minimu}}$} & \multirow{2}{*}{$\underset{\text { maximu }}{\text { Max }}$} & \multicolumn{2}{|c|}{ Percentiles } & \multirow{2}{*}{\begin{tabular}{|c} 
Statistical \\
Significanc \\
$\mathbf{e}$
\end{tabular}} \\
\hline & & & & $25^{\text {th }}$ & $75^{\text {th }}$ & \\
\hline \begin{tabular}{|c} 
Preoperativ \\
e alveolar \\
bone height \\
in mm \\
(BH0) \\
\end{tabular} & 5.750 & 4.5 & 6.2 & 5.475 & 6.050 & $0.005^{* *}$ \\
\hline \begin{tabular}{|c|} 
Alveolar \\
bone height \\
4 months \\
after \\
surgery in \\
mm (BH2) \\
\end{tabular} & 10.550 & 7.0 & 11.2 & $\begin{array}{c}10.00 \\
0\end{array}$ & $\begin{array}{c}11.00 \\
0\end{array}$ & \\
\hline
\end{tabular}

**Statistical Test: Wilcoxon Signed Rank Test $(\mathrm{z}=-2.807)$ ${ }^{* *} \mathrm{p}<0.05$ was considered significant

Table (3): Comparison between initial and final bone gain measurements according to Radiographic bone assessment $(\mathrm{mm})(\mathrm{n}=10)$.

\begin{tabular}{|c|c|c|c|c|c|c||}
\hline & Median & Minimum & Maximum & \multicolumn{2}{|l|}{ Percentiles } & Statistical \\
\cline { 5 - 7 } & $\mathbf{2 5}^{\text {th }}$ & $\mathbf{7 5}^{\text {th }}$ & Significance \\
\hline $\begin{array}{c}\text { Initial bone } \\
\text { gain in mm } \\
\text { (BH1-BH0) }\end{array}$ & 6.470 & 5.5 & 8.1 & 5.950 & 6.750 & 0.008 \\
\hline $\begin{array}{c}\text { Final bone } \\
\text { gain in mm } \\
\text { (BH2-BH0) }\end{array}$ & 4.540 & 1.1 & 6.5 & 4.275 & 5.325 & \\
\hline
\end{tabular}

**Statistical Test: Wilcoxon Signed Rank Test $(\mathrm{z}=-2.500)$

${ }^{* *} \mathrm{p}<0.05$ was considered significant

\section{DISCUSSION}

For ridge augmentation, the autogenous bone grafts are the best option when compared to allografts and xenografts because of less graft rejection and its role in osteogenesis, osteoinduction and osteoconduction.

Many donor sites of autogenous bone grafts are available (21). Among the intraoral donor sites, ramus is the most favorable site used for long-span augmentations. About 25- to 40-mm length bone block can be taken from the ramus. Due to the proximity to the anatomical structures like inferior alveolar nerve, only a limited thickness of graft block can be taken and so this donor site cannot be used for vertical augmentation of severely resorbed site.

Thanks to Cortical tenting technique vertical augmentation of severely resorbed ridges can be achievable $(21,22)$. In this procedure, a single ramus block over the edentulous ridge can be used while maintaining a space underneath to be filled with particulate bone material.

In this study, the bone defects in the posterior mandibular ridge had been reconstructed by autogenous bone blocks taken from the ramus of the mandible using cortical tenting technique (23). 
Cortico-cancellous block grafts have been associated with a decreased rate of revascularization. A lot of studies said that in cortical bone autografts, most of the internal structure was never revascularized or replaced by vital bone. So, they are liable to infection $(24,25)$. Burchardt $(26)$ reported the term "creeping substitution," which is a dynamic reconstructive and healing process of bone. His study showed that the cortico-cancellous autograft is survived with a small amount of resorption, expected to be replaced by bone with time.

A few of osteogenic cells within the harvested bone graft survive and function in the recipient site. So, osteoregeneration within a grafted area mainly depends on the activity of osteogenic cells moved to the recipient bed. A good number of osteogenic cells are only available by proper revascularization of the grafted site, which is considered a major success criterion for grafting procedures (27-29). It has been reported that with particulate bone materials, neoangiogenesis occurs more rapidly than when block grafts are used.

In this study, particulate bone substitutes were used below the cortical block in the tenting technique to increase the revascularization of the area, leading to more favorable augmentation results.

Increase bone height by using autogenous bone grafts has been reported to be favorable in a lot of studies with a similar methodology. Khoury and Khoury (30) could achieve $7.8 \mathrm{~mm}$ of vertical augmentation by securing particulate autogenous bone grafts with cortical ramus blocks.

Proussaefs et al., (31) studied the bone height gain in 8 patients and an average $5.12 \mathrm{~mm}$ of increase bone height (SD1.46) in the mandible was reported. Novy LFS et al., (32) also did a vertical augmentation on thirteen patients using tenting technique and reported $1.6 \mathrm{~mm}$ as final average increase in bone height. Meanwhile in this study, an average $4.54 \mathrm{~mm}$ of increase bone height (SD 1.57) was measured.

This study showed a graft resorption rate of $30 \%$, which is agreed with other studies but some studies showed less resorption rate also (33). Wang and Luo (34) was reported that age was an important factor affecting bone resorption. In this study, the bone resorption rate of patients in the 41 to 50 -yearold age group was $23.0 \%$ on 6 months after the surgery and $32.7 \%$ at the final follow-up time; these were higher than rates of other age groups.

According to Andreasen et al., (35) the gender of the patient was highly related to bone resorption activity. He reported that degree of bone resorption was higher in women than in men.

One major disadvantage of vertical augmentation is the resorption of a large proportion of the graft. Antoun et al., (35) found a remarkable difference in graft resorption, with a mean of $0.3 \mathrm{~mm}$ in the non-resorbable membrane group versus $2.3 \mathrm{~mm}$ in the graft group without membrane use.

Because the use of non-resorbable membranes needs more complex surgical handling of the soft tissues, many authors suggested the use of resorbable collagen membranes and an organic bovine bone to protect the block graft and prevent its resorption.

In this study, a PRF membrane was used to protect the grafted area below the mucoperiosteal flap. Chenchev IL et al., (36) also reported the beneficial application of plateletrich fibrin and injectable platelet-rich Fibrin in combination of bone substitute material for alveolar ridge augmentation.

According to Alkhader $\mathrm{M}$ et al., (37) CBCT was very useful for predicting bone density at posterior mandibular implant sites. J Zhang et al., (38) also reported the importance of CBCT in bone density measurements.

According to S. Schultze-Mosgau et al., (39) 25 patients were subjected to vertical ridge augmentation with autogenous iliac crest bone graft. At the end of healing period of 4.5 months, bone density at grafted area was measured from CT with a median value of 261 Hounsfield unit (HU).

In this study, estimated bone density at grafted area above the recipient site was measured from CBCT with a mean value of 398.59 VV which equaled $279 \mathrm{HU}$ according to $\mathrm{M}$ Cassetta et al., (40) who suggested a conversion ratio to transform the gray density values of CBCT measured in voxel value (VV) to that of CT measured in Hounsfield unit (HU) and that conversion ratio was approximately $0.7(0.7 \times$ values of $\mathrm{CBCT}=$ values of $\mathrm{CT})$.

\section{CONCLUSIONS}

The use of cortical block graft taken from the ramus of the mandible to augment vertical bone defect in the posterior of the mandible has significant success rates.

\section{CONFLICT OF INTEREST}

The authors declare that they have no conflicts of interest.

\section{REFERENCES}

1. Tallgren A. The continuing reduction of the residual alveolar ridges in complete denture wearers: a mixedlongitudinal study covering 25 years. J Prosthet Dent. 1972;27:120-32.

2. Carlsson G, Thilander H, Hedegård B. Histologic changes in the upper alveolar process after extractions with or without insertion of an immediate full denture. Acta Odontol Scand. 1967;25:21-43.

3. Atwood DA. Reduction of residual ridges: a major oral disease entity. J Prosthet Dent. 1971;26:266-79.

4. Li H, Zhou CR, Zhu MY, Tian JH, Rong JH. Preparation and characterization of homogeneous hydroxyapatite/chitosan composite scaffolds via in-situ hydration. J Biomater Nanobiotechnol. 2010;1(01):42-9.

5. Herford AS, Tandon R, Stevens TW, Stoffella E, Cicciu M. Immediate distraction osteogenesis: the sandwich technique in combination with rhBMP-2 for anterior maxillary and mandibular defects. J Craniofac Surg. 2013;24:1383-7.

6. das Neves FD, Fones D, Bernardes SR, do Prado CJ, Neto AJF. Short implants--an analysis of longitudinal studies. Int J Oral Maxillofac Implants. 2006;21:86-93. 
7. Hummel SK, Wilson MA, Marker VA, Nunn ME. Quality of removable partial dentures worn by the adult US population. J Prosthet Dent. 2002;88:37-43.

8. Felice P, Cannizzaro G, Checchi V, Marchetti C, Pellegrino G, Censi P, et al. Vertical bone augmentation versus 7-mm-long implants in posterior atrophic mandibles. Results of a randomised controlled clinical trial of up to 4 months after loading. Eur J Oral Implantol. 2009;2:7-20.

9. Raviv E, Turcotte A, Harel-Raviv M. Short dental implants in reduced alveolar bone height. Quintessence Int. 2010;41:575-9.

10. Higuchi KW, Folmer T, Kultje C. Implant survival rates in partially edentulous patients: a 3-year prospective multicenter study. J Oral Maxillofac Surg. 1995;53:264-8.

11. Simion M, Jovanovic SA, Tinti C, Benfenati SP. Longterm evaluation of osseointegrated implants inserted at the time or after vertical ridge augmentation. A retrospective study on 123 implants with 1-5 year follow-up. Clin Oral Implants Res. 2001;12:35-45.

12. Merli M, Bernardelli F, Esposito M. Horizontal and vertical ridge augmentation: a novel approach using osteosynthesis microplates, bone grafts, and resorbable barriers. Int J Periodontics Restorative Dent. 2006;26:5817.

13. Herford AS, Lu M, Akin L, Cicciù M. Evaluation of a porcine matrix with and without platelet-derived growth factor for bone graft coverage in pigs. Int J Oral Maxillofac Implants. 2012;27:1351-8.

14. Chiapasco M, Zaniboni M, Rimondini L. Autogenous onlay bone grafts vs. alveolar distraction osteogenesis for the correction of vertically deficient edentulous ridges: a 24-year prospective study on humans. Clin Oral Implants Res. 2007;18:432-40.

15. Park SH, Lee Kw, Oh TJ, Misch CE, Shotwell J, Wang HL. Effect of absorbable membranes on sandwich bone augmentation. Clin Oral Implants Res. 2008;19:32-41.

16. $\mathrm{Fu} \mathrm{JH}$, Oh TJ, Benavides E, Rudek I, Wang HL. A randomized clinical trial evaluating the efficacy of the sandwich bone augmentation technique in increasing buccal bone thickness during implant placement surgery: I. Clinical and radiographic parameters. Clin Oral Implants Res. 2014;25:458-67.

17. Le B, Burstein J, Sedghizadeh PP. Cortical tenting grafting technique in the severely atrophic alveolar ridge for implant site preparation. Implant Dent. 2008;17:40-50.

18. Khoury F, Khoury C. Mandibular bone block grafts: diagnosis, instrumentation, harvesting techniques and surgical procedures. In: Khoury F, Antoun H, Missika P, $\mathrm{J}$ Bessade J (eds). Bone augmentation in oral implantology. London , Chicago: Quintessence Pub; 2007.

19. Ozdemir F, Tozlu M, Germec-Cakan D. Cortical bone thickness of the alveolar process measured with cone-beam computed tomography in patients with different facial types. Am J Orthod Dentofacial Orthop. 2013;143:190-6.
20. Morad G, Khojasteh A. Cortical tenting technique versus onlay layered technique for vertical augmentation of atrophic posterior mandibles: a split-mouth pilot study. Implant Dent. 2013;22:566-71.

21. Brugnami F, Caiazzo A, Leone C. Local intraoral autologous bone harvesting for dental implant treatment: alternative sources and criteria of choice. Keio J Med. 2009;58:24-8.

22. Misch CM. Use of the mandibular ramus as a donor site for onlay bone grafting. J Oral Implantol. 2000;26:42-9.

23. Deshpande S, Deshmukh J, Deshpande S, Khatri R, Deshpande S. Vertical and horizontal ridge augmentation in anterior maxilla using autograft, xenograft and titanium mesh with simultaneous placement of endosseous implants. J Indian Soc Periodontol. 2014;18:661-5.

24. Enneking WF, Eady JL, Burchardt H. Autogenous cortical bone grafts in the reconstruction of segmental skeletal defects. J Bone Joint Surg Am. 1980;62:1039-58.

25. Hammack BL, Enneking WF. Comparative vascularization of autogenous and homogenous-bone transplants. J Bone Joint Surg Am. 1960;42-A:811-7.

26. Burchardt $H$. The biology of bone graft repair. Clin Orthop Relat Res. 1983;:28-42.

27. Hallman M, Thor A. Bone substitutes and growth factors as an alternative/complement to autogenous bone for grafting in implant dentistry. Periodontol 2000. 2008;47:172-92.

28. Einhorn TA, Lee CA. Bone regeneration: new findings and potential clinical applications. J Am Acad Orthop Surg. 2001;9:157-65.

29. Kim ES, Kim JJ, Park EJ. Angiogenic factor-enriched platelet-rich plasma enhances in vivo bone formation around alloplastic graft material. J Adv Prosthodont. 2010;2:7-13.

30. Khoury F KC. Mandibular bone block grafts: Diagnosis, instrumentation, harvesting technique and surgical procedures. In: Khoury F, Antoun H, Missika P, Bessade J (eds). Bone Augmentation in Oral Implantology. London, Chicago: Quintessence Pub. 2007:169-83.

31. Proussaefs P, Lozada J. The use of intraorally harvested autogenous block grafts for vertical alveolar ridge augmentation: a human study. Int $\mathrm{J}$ Periodontics Restorative Dent. 2005;25:351-63.

32. Novy LFS, Aguiar EG, de Arruda JAA, de Castro MAA, Moreira AN, Dos Santos EG, et al. Linear and volumetric gain after vertical bone augmentation in the posterior mandible using an autologous cortical tenting method. Int J Oral Maxillofac Surg. 2019;48:1485-91.

33. Peng W, Kim I-K, Cho H-Y, Pae S-P, Jung B-S, Cho H$\mathrm{W}$, et al. Assessment of the autogenous bone graft for sinus elevation. J Korean Assoc Oral Maxillofac Surg. 2013;39:274-82.

34. Wang $X$, Luo $Y$. Influencing factors on bone resorption after alveolar bone grafting. Zhonghua Kou Qiang Yi Xue Za Zhi 2005;40:373-5. 
35. Antoun H, Sitbon JM, Martinez H, Missika P. A prospective randomized study comparing two techniques of bone augmentation: onlay graft alone or associated with a membrane. Clin Oral Implants Res. 2001;12:632-9.

36. Chenchev IL, Ivanova VV, Neychev DZ, Cholakova RB. Application of Platelet-Rich Fibrin and Injectable PlateletRich Fibrin in Combination of Bone Substitute Material for Alveolar Ridge Augmentation - a Case Report. Folia Med (Plovdiv). 2017;59:362-6.

37. Alkhader M, Hudieb M, Khader Y. Predictability of bone density at posterior mandibular implant sites using conebeam computed tomography intensity values. Eur J Dent. 2017;11:311-6.
38. Zhang J, Tian Y, Liu Y, Liu Q, Zhang J, Liu J, et al. Alveolar Bone Mineral Density Measurement using CBCT Images. Neuroscience and Biomedical Engineering. 2017;5(1):44-9.

39. Schultze-Mosgau S, Keweloh M, Wiltfang J, Kessler P, Neukam F. Histomorphometric and densitometric changes in bone volume and structure after avascular bone grafting in the extremely atrophic maxilla. British Journal of Oral and Maxillofacial Surgery. 2001;39(6):439-47.

40. Cassetta M, Stefanelli LV, Pacifici A, Pacifici L, Barbato E. How accurate Is CBCT in measuring bone density? A comparative CBCT - CT in vitro study. Clinical implant dentistry and related research. 2014;16(4):471-8. 